\title{
Deformidade de Kirner «invertida». Um caso
}

\author{
J. C. Botelheiro(1), S. Silvério( ${ }^{(2)}$, F. Leitão(2) \\ (I)ASSIT. GRAD. DE ORTOPEDIA. \\ ${ }^{(2)}$ INTERNOS DE ORTOPEDIA. \\ Unidade de Cirugia da Mão, Hospital de Sant' Ana, Parede, Portugal
}

Correspondencia:

Jose Carlos Botelheiro

Hospital de Sant'Ana

2779-501 Parede, PORTUGAL

Tel.: 351214585600

Fax.: 351214585601

E-mail: hosa@clix.pt

Observamos un niño de 11 años, sin otras anomalías que tenía una pronunciada cuvatura dorsal de la tercera falange del meñique derecho, que se podría denominar «deformidad de Kirner invertida». Fue operado osteotomía doble fijada con una aguja de Kirchner, con mejoría cosmética y funcional aceptable.
We observed a dorsal curvature of the last phalanx of the fifith finger of the right hand of an eleven year boy that could be described as a «reverse Kirner deformity» and was operated with a fair result. deformidade de Kirner é uma curvatura palmar e radial da falange distal do auricular, com a unha «em garra», apresentando-se na preadolescência, indolor, mais

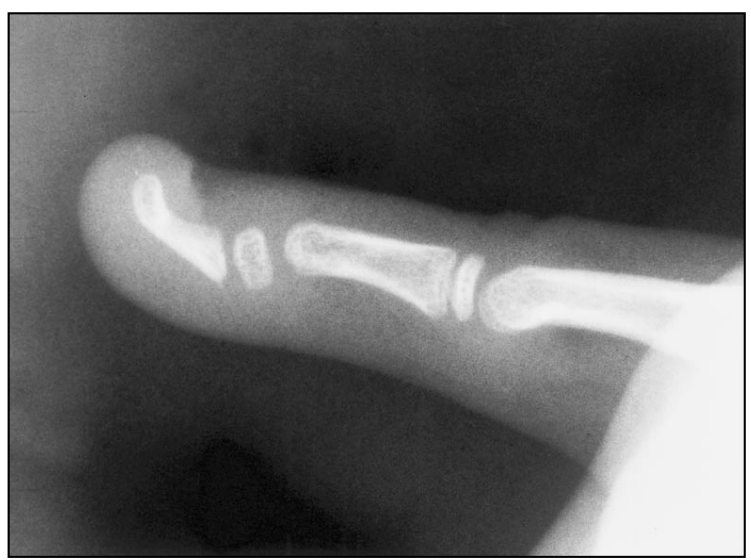

Figura 1. Radiografia pré-operatória. comum no sexo feminino e muitas vezes bilateral, de etiologia ainda desconhecida (Carsten and Eiken, 1970; Dobyns et al., 1992; Minguella, 2000; Ogino, 1998).

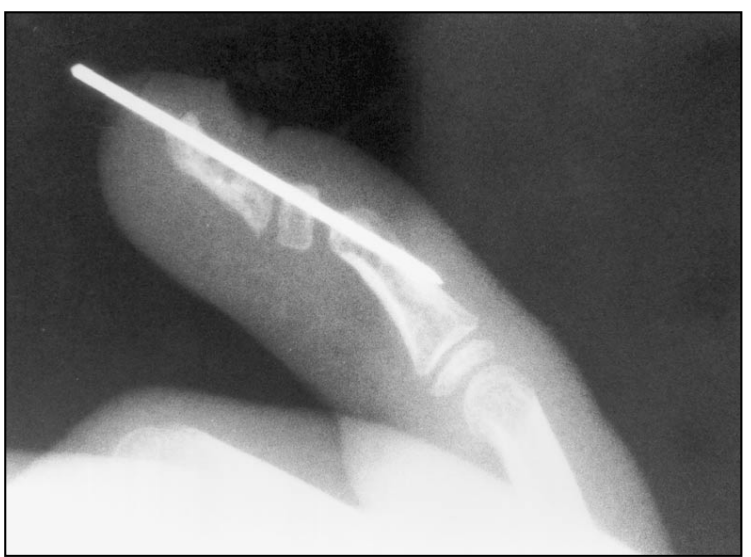

Figura 2. Radiografia post-operatória. 
Observamos uma patologia semelhante mas com uma curvatura dorsal, unilateral, sem antecedente traumático, no auricular direito de um rapaz de 11 anos sem outras anomalias — uma «deformidade de Kirner invertida» (Figura 1) - que não foi ainda descrita, que tenhamos conhecimento, e que não pode ser atribuída a uma anormal inserção do tendão flexor profundo como foi a doença de Kirner (Carsten and Eiken, 1970).

Foi feita a sua correcção cirúrgica com uma osteotomia dupla de abertura dorsal, por via lateral, fixada com um fio de Kirchner (Carsten and Eiken, 1970) (Figura 2), obtendo-se uma correcção parcial da deformidade (Figura 3).

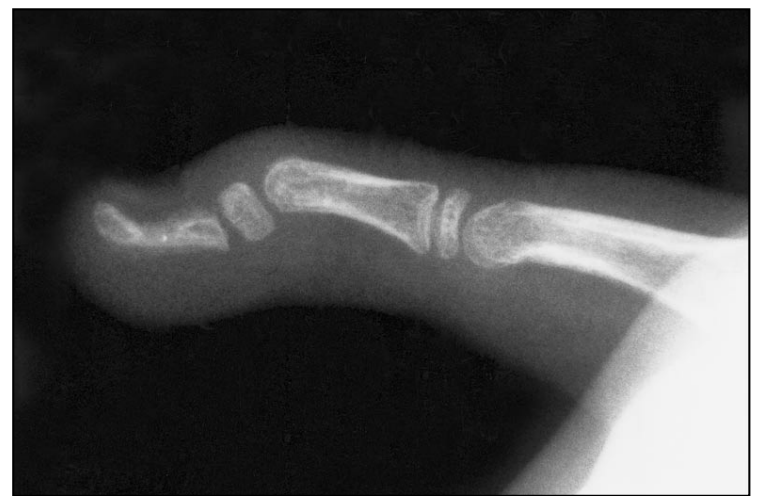

Figura 3. Radiografia final.

\section{BIBLIOGRAFÍA}

Carstam, N.; Eiken, O. (1970): Kirner's deformity of the little finger. Journal of Bone and Joint Surgery 52A: 1663-1665.

Dobyns, J. H.; Wood, V. E.; Bayne, L. G.; Frykman: Congenital Hand Deformidies. In: Green
DP (ed.) Operative Hand Surgery.New York Churchill Livingstone, 1982, Vol I: 353355.

Miguella, J.: Malformaciones de la mano. Barcelona, Masson edit., 2000: 147-149.
Ogino, T.: Bone and Joint Deformities. In: Buck-Gramko D. (ed.) Congenital Malgormations of the Hand and Forearm. London Curchill Livingstone, 1998; 337-339. 